\title{
Inhaled corticosteroids and pulmonary sarcoidosis
}

\section{To the Editor:}

We read with interest the paper by AlberTs et al. [1] in the May issue of the Journal. They showed that inhaled budesonide, 1,200 $\mu \mathrm{g}$ once daily, was significantly superior to placebo in increasing vital capacity (VC) and reducing symptoms in patients with newly diagnosed pulmonary sarcoidosis with an initially reduced lung function. The improvements in VC in this study are of the same magnitude as the best results obtained in placebocontrolled studies with oral corticosteroids [2]. In a Danish study an increase in mean VC from 4.0 to $4.9 \mathrm{~L}$ has been reported but compared with placebo this increase did not reach a level of statistical significance because of the small number of patients included [3].

Accompanying the paper by AlBerTs et al. [1] was an editorial by KIRSTEN [4], which unfortunately had a number of errors and was also limited in reference to published papers. We would, therefore, like to add information related to this topic.

Firstly, some corrections: AlBERTs et al. [1], as well as SPITERI et al. [5], used inhaled budesonide, 1,200 and $1,600 \mu \mathrm{g}$ daily, respectively, given as pressurized metereddose inhalers (pMDI) attached to a large volume spacer (Nebuhaler®) and not via nebulizer. The experiences of GUPTA [6] refer to beclomethasone dipropionate (BDP) and not to budesonide, which is important as these two inhaled corticosteroids have different lung pharmacokinetic profiles. GUPTA [6] also found BDP less interesting, as Indian sarcoidosis patients usually have extrapulmonary manifestations which cannot be treated with inhaled steroids. KIRSTEN [4] also wrote that in the study by AlBERTs et al. [1] "11 patients (23\%) had to be switched to oral prednisolone, and this did not depend on whether patients had received inhaled budesonide or placebo". Although this is true, the five patients who had to be given prednisolone because of objective measurements - lung function deteriorations - had all been treated with placebo and that difference was statistically significant.

There is quite a large number of published studies with budesonide in pulmonary sarcoidosis, and they have been recently reviewed [2]. To document the efficacy of a drug in pulmonary sarcoidosis is difficult as patients may have spontaneous recoveries. Therefore, at a meeting in London in 1984 under the chairmanship of Professor Margaret Turner-Warwick it was suggested that, if present, documented efficacy of an inhaled corticosteroid could be best demonstrated by treating relapses occurring after discontinuation of oral corticosteroids, as spontaneous recoveries are unknown in this clinical situation. In a series of 12 patients with relapsing pulmonary sarcoidosis inhaled budesonide alone was found to be effective in eight $[7,8]$ and an oral steroid sparing capacity was also documented [9].

In the early studies with budesonide, it was quite obvious that improvements did not take place as rapidly as usually seen with 40-60 mg prednisolone [10], although the results after treatment for 18 months were comparable to results obtained with oral steroids [2]. Twenty patients with pulmonary stage II-III sarcoidosis were, therefore, given oral steroids for 3 months, followed by inhaled budesonide for 15 months. The results were compared with a historical series of matched controls treated with oral steroids for 18 months. No difference could be found between the two series [11]. This treatment strategy - oral steroids for 3 months followed by inhaled budesonide - has been successfully documented in double-blind, placebo-controlled studies [11-13]. We have recently reported on our positive experiences of using methylprednisolone for 6-8 weeks followed by budesonide for 18 months in a series of 47 patients [14].

In double-blind, placebo-controlled studies, inhaled budesonide has been found to reduce the number and proportion of T-lymphocytes in the bronchoalveolar lavage (BAL) fluid and to normalize the increased CD4+/CD8+ ratio $[5,15]$. Budesonide reduced the concentration of hyaluronan in the BAL fluid, which could be a marker of early fibroblast activation [15]. Finally, a normalization of BAL macrophage subpopulations with a decrease in antigen-presenting macrophages has been found [5]. These findings indicate that inhaled budesonide may influence early and pathogenetically important processes in pulmonary sarcoidosis.

\section{References}

1. Alberts C, van der Mark ThW, Jansen HM. Inhaled budesonide in pulmonary sarcoidosis: a double-blind, placebo-controlled study. Eur Respir J 1995; 8: 682-688.

2. Brattsand R, Selroos O. Current drugs for respiratory diseases. glucocorticosteroids. In: Page CP, Metzger WJ, eds. Drugs and the lung. New York, Raven Press, 1994; pp. 101-220.

3. Milman N, Graudal N, Munch E. No effect of highdose inhaled steroids in pulmonary sarcoidosis: a double-blind, placebo-controlled study. J Intern Med 1994; 236: 285-290.

4. Kirsten D. Inhaled steroids for sarcoidosis? Eur Respir $J$ 1995; 8: 679-681.

5. Spiteri MA, Newman SP, Clarke SW, Poulter LW. Inhaled corticosteroids can modulate the immunopathogenesis of sarcoidosis. Eur Respir J 1989; 2: 218-224.

6. Gupta SK. Treatment of sarcoidosis patients by steroid aerosol: a 10 year prospective study from Eastern India. Sarcoidosis 1989; 6: 51-54. 
7. Selroos O. Relapsing pulmonary stage II-III sarcoidosis can be treated with inhaled budesonide. (Abstract). Am Rev Respir Dis 1987; 135: A349.

8. Selroos O. Use of budesonide in the treatment of pulmonary sarcoidosis. In: Ellul-Micallef R, Lam KW, Toogood JH, eds. Advances in the use of inhaled corticosteroids. Hong Kong, Exerpta Medica, 1987; pp. 188-197.

9. Morgan AD, Johnson MA, Kerr I, Turner-Warwick M. The action of an inhaled corticosteroid as a steroid sparing agent in chronic pulmonary sarcoidosis. (Abstract). Am Rev Respir Dis 1987; 135: A349.

10. Selroos O. Use of budesonide in the treatment of pulmonary sarcoidosis. Ann NY Acad Sci 1986; 465: 713 721.

11. Selroos O. Further experiences with inhaled budesonide in the treatment of pulmonary sarcoidosis. In: Grassi C, Rizzato G, Pozzi E, eds. Sarcoidosis and other
Granulomatous Disorders. Amsterdam, Elsevier Science, 1988; pp. 637-640.

12. Zych D, Pawlicka L, Zielinski J. Inhaled budesonide $v s$ prednisolone in the maintenance treatment of pulmonary sarcoidosis. Sarcoidosis 1993; 10: 56-61.

13. Tolokh O, Ilnitsky I, Hobzey M. Comparison of prednisone and budesonide in the treatment of pulmonary sarcoidosis. Tubercle Lung Dis 1994; 75 (Suppl. 1): 101.

14. Selroos O, Löfroos A-B, Pietinalho A, Niemistö M, Riska $\mathrm{H}$. Inhaled budesonide for maintenance treatment of pulmonary sarcoidosis. Sarcoidosis 1994; 11: 126-131.

15. Erkkilä S, Fröseth B, Hellström P-E, et al. Inhaled budesonide influences cellular and biochemical abnormalities in pulmonary sarcoidosis. Sarcoidosis 1988; 5: 106-110.

\section{A. Pietinalho*, O. Selroos**}

Mjölbolsta Hospital, FIN-10350 Karis, Finland. **AB Astra Draco, S-22100 Lund, Sweden.

\section{REPLY}

\section{From the authors:}

First, I would like to thank Anne Pietinalho and Olof Selroos for their comments relating to the paper by AlberTs et al. [1] and the Editorial [2], published in the May issue of the Journal on the topic of inhaled corticosteroids and pulmonary sarcoidosis. I am also grateful for the correction of some writing errors (BDP instead of budenoside, Nebulizer instead of Nebuhaler). In my opinion, however, this does not influence the general message, even though there are some minor differences between BDP and budenoside, which are probably of negligible clinical relevance.

With regard to those patients, in the study by AlBERTS et al. [1], who were switched from inhaled to oral steroids (23\%), we have to look at the criteria for therapy decisions: these are lung function deterioration and patients' complaints. I am surprised that in their comments Drs Pietinalho and Selroos regard lung function impairment to be more important than symptoms, since in their own study [3], published in Sarcoidosis, a number of the steroid-treated sarcoidosis patients with roentgenological stage II and III had normal lung function parameters and were treated mainly for their symptoms.

Additionally, the treatment strategy with oral steroids for 2-3 months followed by inhaled steroids does not, in my view, sufficiently, elucidate the role of inhaled steroids for a systemic disease, such as sarcoidosis with a high rate of spontaneous resolution.

The Editorial naturally only acknowledged papers which were peer-reviewed and this may be the reason that some publications did not appear (see Reference list of the letter to the editor $[7-9,11])$.

I think, we agree that further longer term studies of inhaled therapy with steroids in sarcoidosis should be undertaken. Such studies should be performed as multicentre trials, probably at an international level, and should ideally not depend on funding by the pharmaceutical industry.

\section{References}

1. Alberts C, van der Mark ThW, Jansen HM. Inhaled budenosid in pulmonary sarcoidosis: a double-blind, placebo-controlled study. Eur Respir J 1995; 8: 628-688.

2. Kirsten D. Inhaled steroids for sarcoidosis? Eur Respir $J$ 1995; 8: 679-681.

3. Selroos O, Löfroos A-B, Pietinalho A, Niemisto M, Riska $\mathrm{H}$. Inhaled budenoside for maintenance treatment of pulmonary sarcoidosis. Sarcoidosis 1994; 11: 126-131.

\section{Kirsten}

Wöhrendamm 80, Krankenhaus Großhansdorf, D-22927 Großhansdorf, Germany. 